\title{
Exploración física toracopulmonar Proyecto tutorial-interactivo 1
}

\author{
Renata Báez-Saldaña, ** Sergio Monraz-Pérez, ** Teresa Fortoul-Van der Goes, ${ }^{*}$ Patricia Castillo-González,* \\ Uriel Rumbo-Nava,* Rogelio García-Torrentera,* Rebeca Ortiz-Siordia*凶
}

*Instituto Nacional de Enfermedades Respiratorias Ismael Cosío Villegas, Ciudad de México; ثniversidad Nacional Autónoma de México. Trabajo recibido: 04-V-2016; aceptado: 16-VI-2016

RESUMEN. En el año 2004, el INER integró un grupo de trabajo conformado por una médica especialista y una pedagoga, quienes elaboraron un guión instruccional llamado exploración física toracopulmonar. Posteriormente, un equipo del mismo instituto especializado en producción audiovisual y diseño gráfico, fue encargado de diseñar la producción y animación de un audio video (interactivo:http://www.iner.salud.gob. $\mathrm{mx}$ /exploracionfisicatoracopulmonar.aspx). Este video está dirigido a los estudiantes de medicina, profesionistas y médicos especialistas afines. Su fundamento pedagógico está basado en las teorías del aprendizaje conductista, cognitivista y constructivista, considerando que los audiovideos interactivos para la enseñanza no sólo contribuyen al aprendizaje de alumnos matriculados en la modalidad a distancia, sino que también pueden formar parte de los materiales de apoyo en los cursos presenciales y en la formación de posgrado, ya que proporcionan al profesional de medicina los elementos para su actualización en las maniobras fundamentales de la práctica en medicina, en este caso, la exploración física del tórax como parte del abordaje del diagnóstico de las enfermedades del aparato respiratorio. Para lograr este objetivo se describen en el audiovideo las líneas y regiones del tórax, así como las etapas de la exploración física: inspección, palpación, percusión y auscultación.

Palabras clave: Exploración física del tórax, pedagogía, aprendizaje, audiovideo, líneas, regiones, inspección, palpación, percusión y auscultación, tórax.

ABSTRACT. In 2004, National Institute of Respiratory Diseases joined a working group formed by a medical specialist and educator who developed an instructional script called thoraco-pulmonary physical examination. Later, a team of the same institute specialized in audiovisual production and graphic design, were commissioned to design the production and animation of a video (interactive: http: //www.iner. salud.gob.mx/exploracionfisicatoracopulmonar.aspx). The video is aimed at medical students, professionals and related medical specialists. Its pedagogical foundation is based on the theories of behavioral, cognitive and constructivist learning, considering that interactive audiovideos for teaching not only contribute to the learning of students enrolled in distance learning, but can also be part of the supporting materials in classroom and postgraduate training courses, as they provide professional medical items for update on fundamental practice maneuvers in medicine, in this case, physical examination of the chest as part of the approach to the diagnosis of respiratory diseases. To achieve this goal we described in the video the lines and regions of the thorax, and the stages of physical examination: inspection, palpation, percussion and auscultation.

Key words: Physical examination of the chest, teaching, learning, audiovideo, lines, regions, inspection, palpation, percussion and auscultation, thorax.

\section{ANTECEDENTES}

La orientación mediatizada como apoyo al adulto en formación, en este caso el proceso de aprendizaje de los médicos en formación, fue el motor para integrar un

\footnotetext{
${ }^{1}$ El material interactivo que se describe a continuación se encuentra a disposición del lector en el Portal del INER en la siguiente liga: http://www.iner.salud.gob.mx/exploracionfisicatoracopulmonar.aspx y sólo se puede ejecutar en ambiente Windows.
}

equipo interdisciplinario que colaboró en la planeación, diseño y producción de un interactivo que favorecerá el aprendizaje y desarrollo de competencias para realizar de manera adecuada las maniobras relacionadas con la semiología y exploración física del tórax, parte fundamental de la atención médica durante la elaboración de la historia clínica.

En el año 2004, en el Instituto Nacional de Enfermedades Respiratorias Ismael Cosío Villegas, Ciudad de México, se integró un grupo de trabajo 
conformado por un médico especialista en neumología y una pedagoga quienes trabajaron cada uno en sus áreas de especialidad en un guión instruccional, mismo que orientó el proceso de producción del trabajo que se describe en la presente revisión. A continuación, un equipo especializado en producción audiovisual y diseño gráfico en el área médica, con base en el guión realizó la toma de audio y video así como el diseño de imágenes y animaciones que darían paso al tutorial sobre «Exploración física toracopulmonar».

(Ver interactivo en: http://www.iner.salud.gob.mx/ exploracionfisicatoracopulmonar.aspx)

El fundamento pedagógico en el que se basó el diseño del guión partió de la revisión de las teorías del aprendizaje conductista, cognitivista y constructivista. Debido a que tanto el contenido como la estructura del tutorial sería autoadministrado se tomó en cuenta que «los estudiantes están expectantes en su función de participantes automotivados, autodirigidos, interactivos... En función de su situación de separación física del docente». ${ }^{1}$

Casi siempre la interactividad se asocia con la educación a distancia en la que los materiales multimedia se diseñan para favorecer el aprendizaje autónomo, mediado por diversos materiales que trasmiten tanto los fundamentos teóricos como los conocimientos y habilidades que favorecen el desarrollo de las competencias definidas en un plan de estudios.

Sin embargo, vale la pena considerar que los interactivos no sólo contribuyen con el aprendizaje de los alumnos matriculados en la modalidad a distancia, también pueden formar parte de los materiales de apoyo de los cursos, considerando como señala Fainholc "existen en las situaciones pedagógicas otras distancias a veces, mas ocultas que deberían ser consideradas».2

Ahora bien, considerando que en la formación médica de la licenciatura, el pilar del futuro profesionista es el aprendizaje autónomo desde el pregrado y que se acentúa en la formación de posgrado, e idealmente se mantiene durante el ejercicio profesional, es importante valorar la aportación que estos materiales debidamente elaborados y actualizados, proporcionan al profesional de la salud elementos para recordar y/o actualizar maniobras fundamentales e inseparables de la atención médica que se describen a continuación.

\section{INTRODUCCIÓN}

La exploración física del tórax es un arte, el cual requiere de sensibilidad y destreza por parte del médico para detectar la presencia de cambios anatómicos indicativos de un probable problema de salud. La sensibilidad y destreza se van adquiriendo durante el ejercicio de la práctica médica. Su utilidad radica en detectar signos de enfermedad, que al ubicarlos en un marco anatómico de referencia permite integrar síndromes.

El presente trabajo tiene como finalidad ofrecer al estudiante de medicina, el conocimiento completo y ordenado sobre las técnicas de exploración física para el abordaje del diagnóstico de las enfermedades del aparato respiratorio. Para ello se describen primero las líneas y regiones del tórax y posterior, las etapas de la exploración física: inspección, palpación, percusión y auscultación.

\section{LÍNEAS Y REGIONES DEL TÓRAX}

- Para una adecuada exploración física del tórax, en primer lugar es conveniente conocer las líneas y regiones que permiten la localización topográfica de las alteraciones pleuropulmonares; de forma tal que, al ubicarlas se haga posible el seguimiento de la secuencia sistemática y ordenada de la exploración.

\section{Líneas del tórax}

\section{Líneas de la cara anterior del tórax}

- Medioesternal. Se localiza en la parte media del esternón, desciende a lo largo de su eje desde

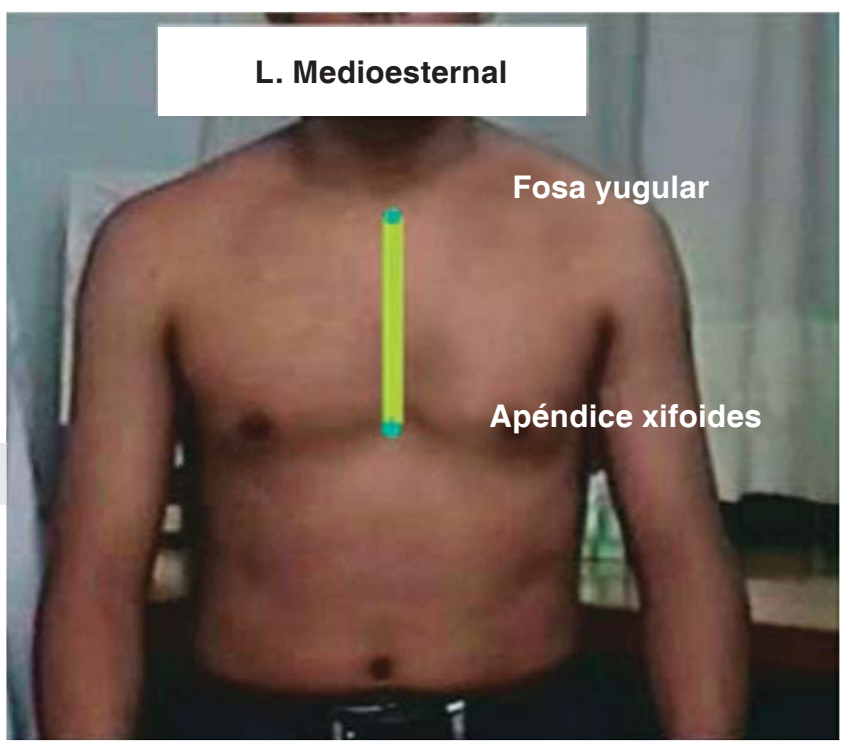

Figura 1. Línea medioesternal. 
la fosa yugular hasta el apéndice xifoides (figura 1).

- Paraesternal. Se inicia en la articulación esternoclavicular y sigue todo el borde esternal derecho e izquierdo (figura 2).

- Medioclavicular. Desciende desde la mitad de la distancia entre las articulaciones esternoclavicular y acromioclavicular (figura 3).

Las líneas clavicular, tercera costal y sexta costal se proyectan en la cara anterior del tórax siguiendo el trayecto anatómico respectivo para cada caso.

\section{Líneas de la cara lateral del tórax}

- La pared lateral del tórax está limitada por las líneas axilar anterior y posterior y entre ambas posteriores, la pared torácica posterior (figuras 4 y 5$)$.

- Axilar anterior. Ésta baja verticalmente a partir del punto en el que el borde inferior del músculo pectoral mayor forma un ángulo con la pared lateral del tórax con el brazo horizontal. La parte anterior del tórax está limitada por ambas líneas axilares anteriores (figura 6).

- Axilar media. Es una vertical descendente que parte del vértice de la axila.

- Axilar posterior. Baja en dirección vertical desde el borde inferior del músculo gran dorsal con el brazo en posición horizontal (figura 7).

\section{Líneas de la cara posterior del tórax}

- Línea vertebral. Es la vertical que sigue el trayecto de las apófisis espinosas de las vértebras (figura 8).

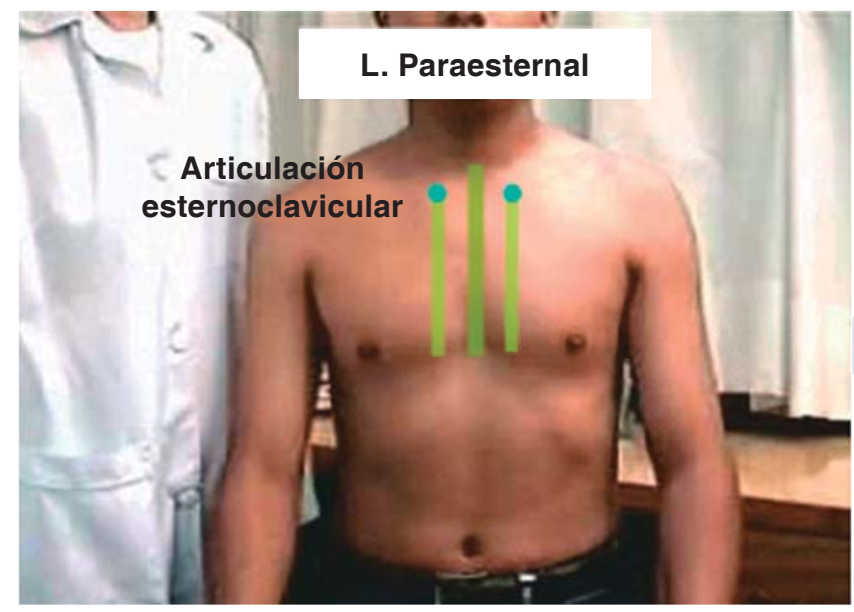

Figura 2. Línea paraesternal.

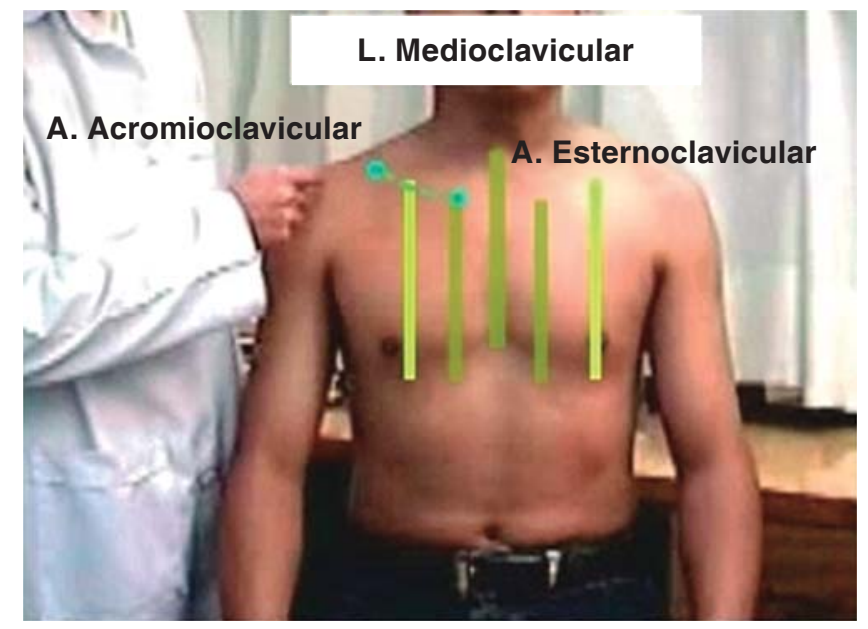

Figura 3. Línea medioclavicular.

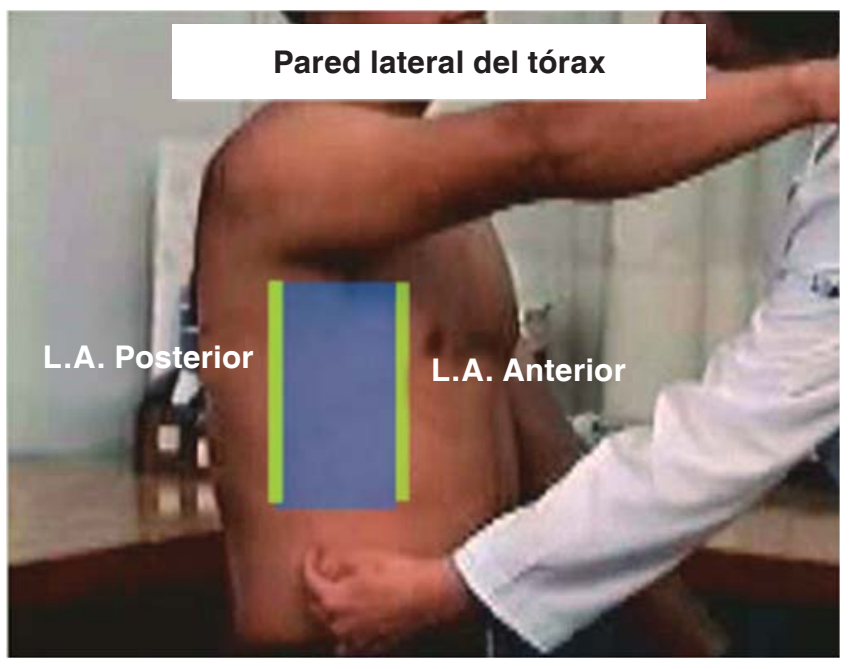

Figura 4. Pared lateral del tórax.

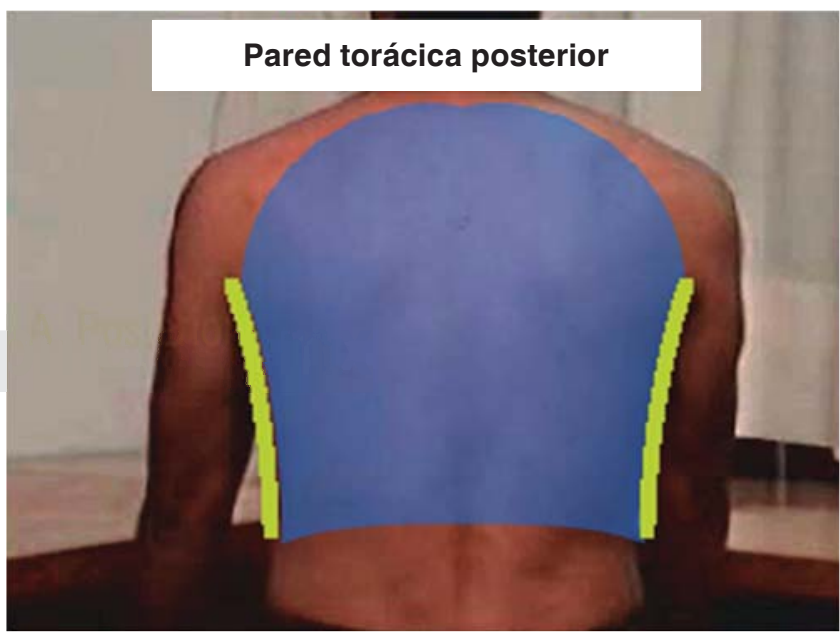

Figura 5. Pared torácica posterior. 


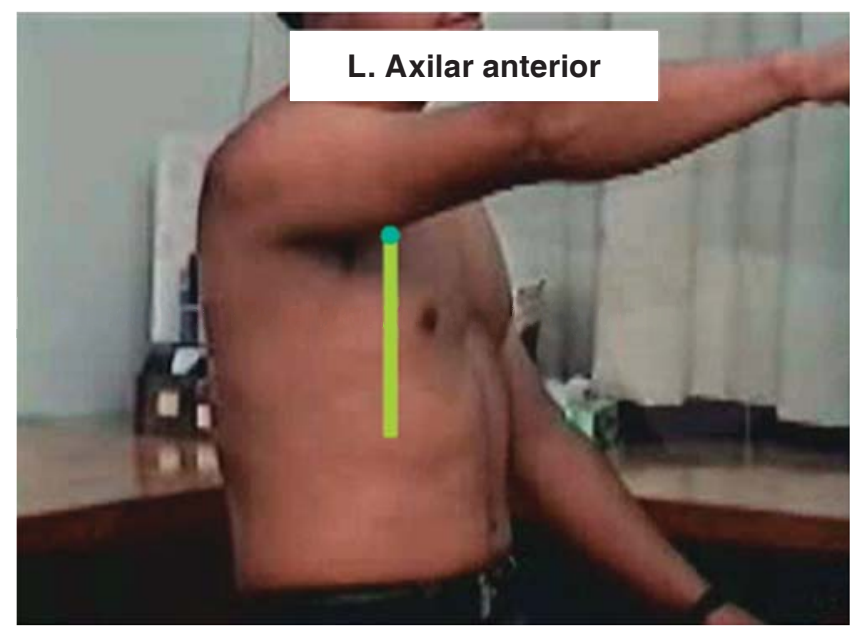

Figura 6. Línea axilar anterior.

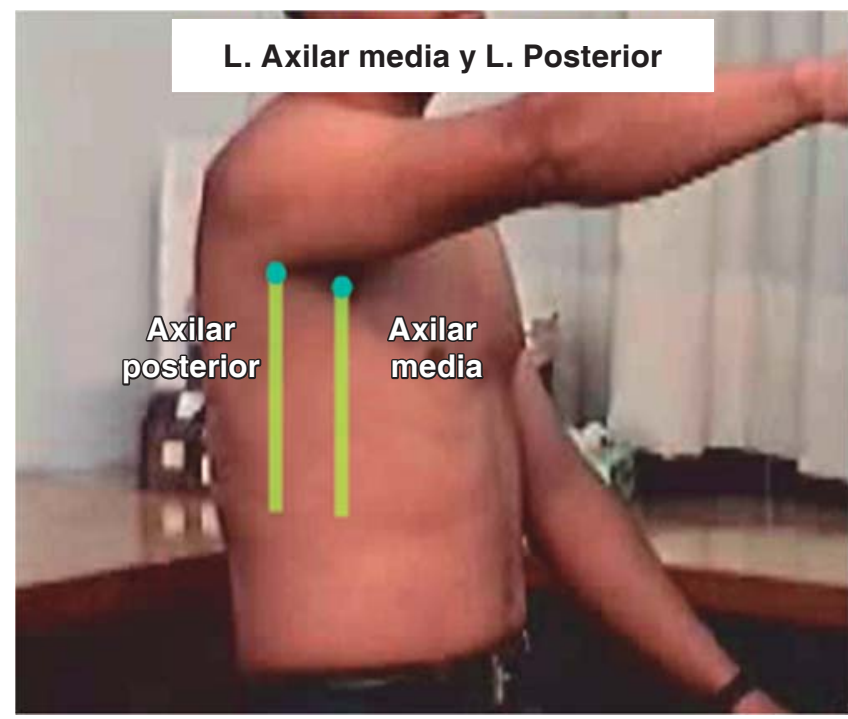

Figura 7. Línea axilar media y línea axilar posterior.

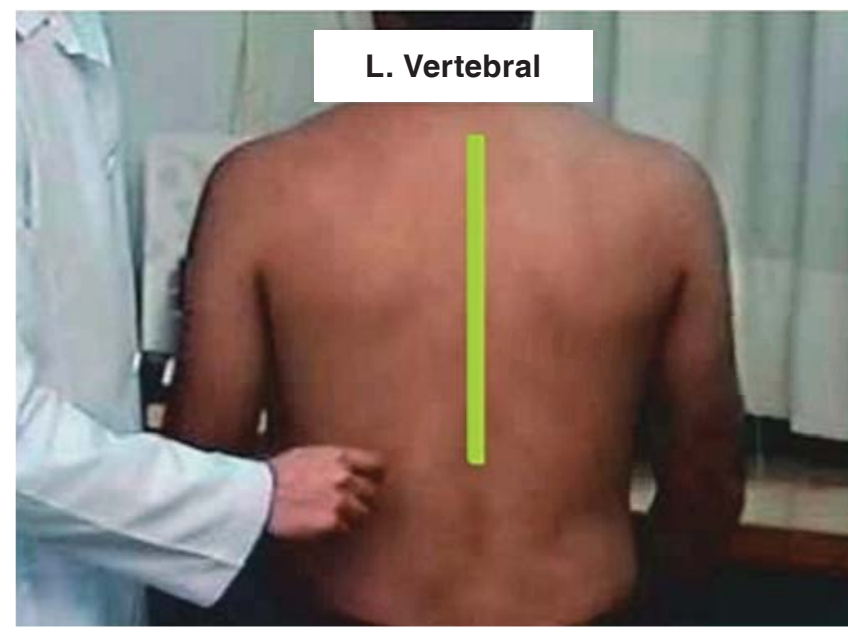

Figura 8. Línea vertebral.
- Líneas escapulares. Pasan por el borde interno de cada una de las escápulas. Las hay derecha e izquierda (figura 9).

- Línea escapuloespinal. Horizontal que sigue la espina de la escápula, señala el cruce de la apófisis espinosa de la tercera vértebra dorsal y constituye el punto de referencia del origen de las cisuras pulmonares (figura 10).

- Línea infraescapular. Línea horizontal que pasa por la parte inferior de la escápula, pasa entre la VII y VIII apófisis espinosas dorsales (figura 11).

- Línea duodécima dorsal o basal de Mouriquand. Corresponde al límite inferior del tórax, la línea se traza con una horizontal a nivel de las duodécimas

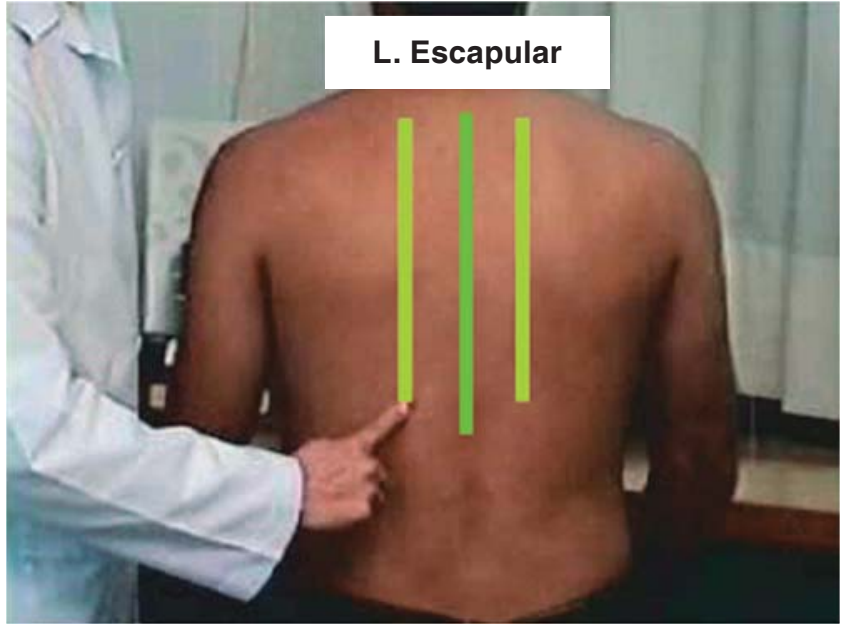

Figura 9. Línea escapular.

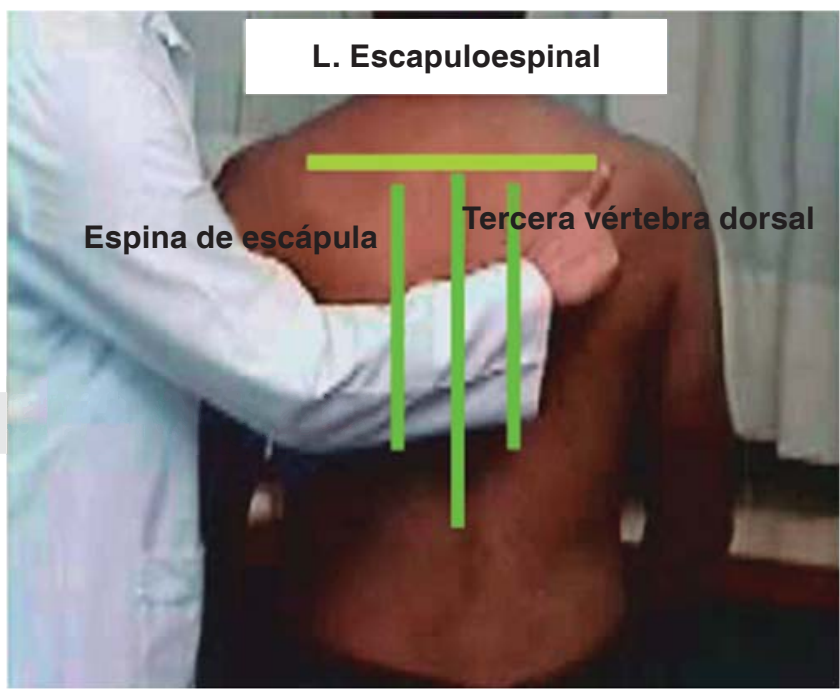

Figura 10. Línea escapuloespinal. 
costillas derecha e izquierda. Esta línea se desplaza dos a tres centímetros durante la inspiración y espiración (figura 12).

\section{Regiones del tórax}

Las regiones del tórax están limitadas por las líneas del tórax descritas previamente y son las siguientes:

\section{Regiones de la cara anterior del tórax}

- Región supraclavicular. Esta región está limitada por la clavícula, el borde superior del músculo trapecio y el posterior del esternocleidomastoideo. Esta región corresponde al vértice del pulmón,

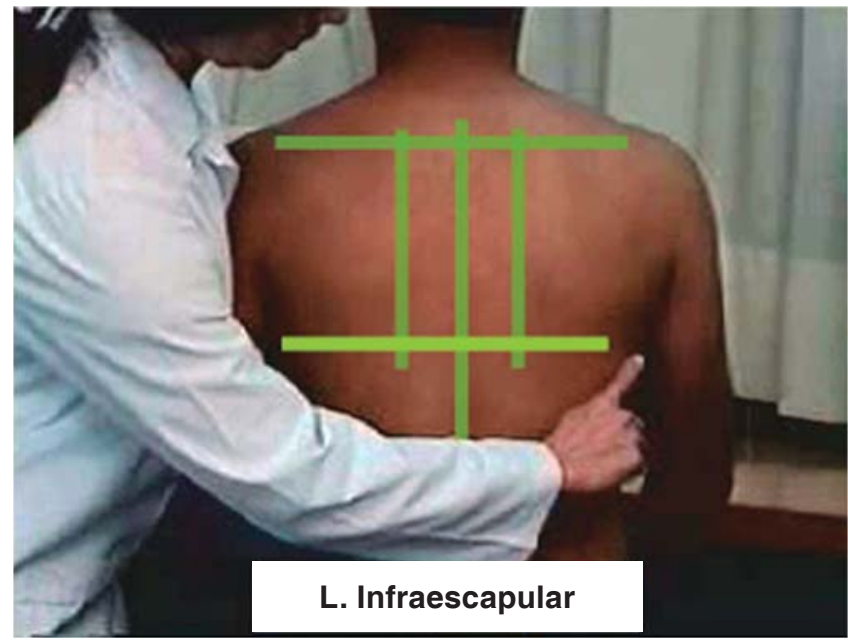

Figura 11. Línea infraescapular.

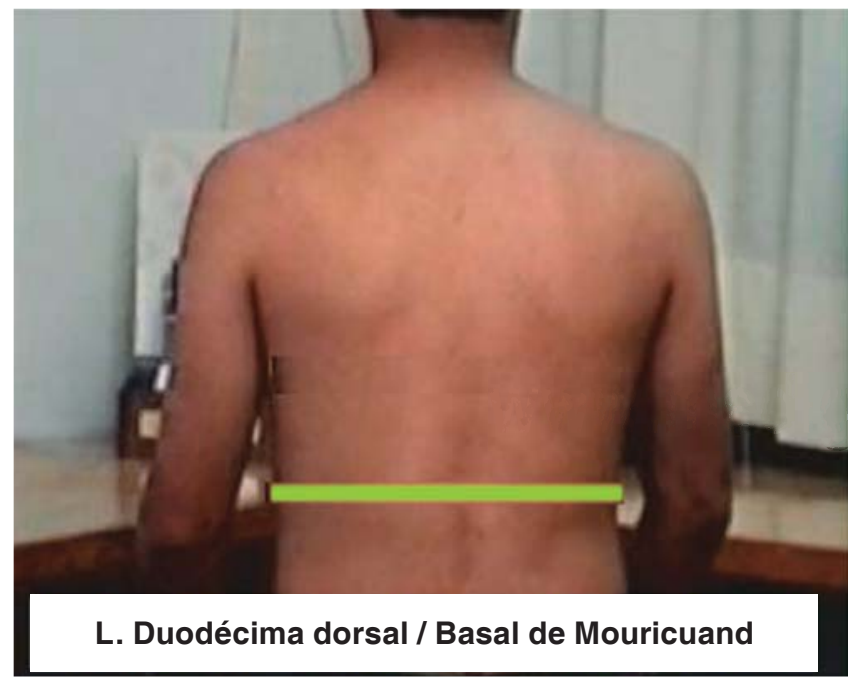

Figura 12. Línea duodécima dorsal o basal de Mouricuand. el cual sobresale de la clavícula $2-4 \mathrm{~cm}$ (figura 13).

- Región supraesternal. Se limita por la parte superior de la horquilla esternal y el borde anterior de ambos músculos esternocleidomastoideos (figura 14).

- Región infraclavicular. Sus límites incluyen al borde inferior de la clavícula, el superior de la tercera costilla, la línea medioesternal y la axilar anterior (figura 15).

- Región mamaria. En ella se encuentra la inserción de la mama y comprende el borde inferior de la región infraclavicular y por debajo por una horizontal a la altura de la sexta costilla (figura 16).

\section{Regiones de la cara lateral del tórax}

- Región axilar. Las líneas axilares anterior y posterior la limitan a los lados; los límites superior e inferior

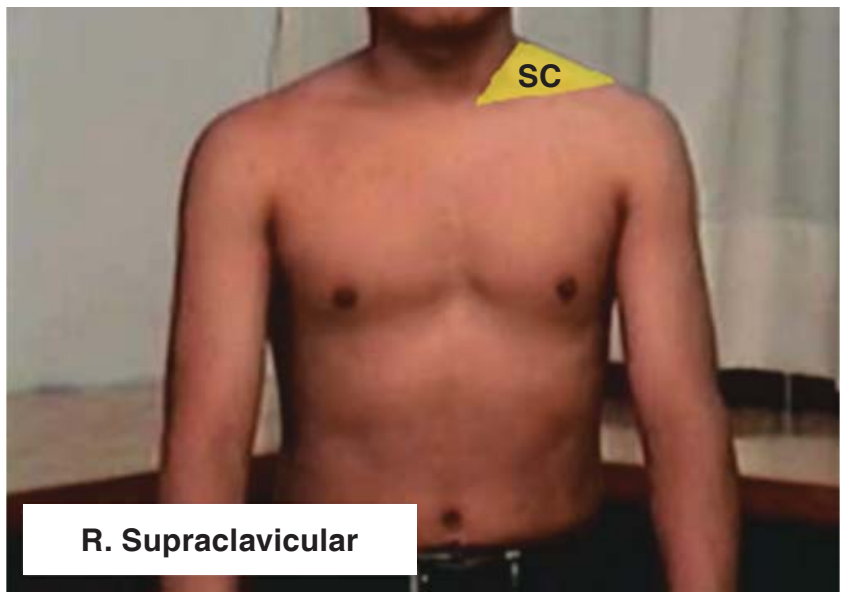

Figura 13. Región supraclavicular.

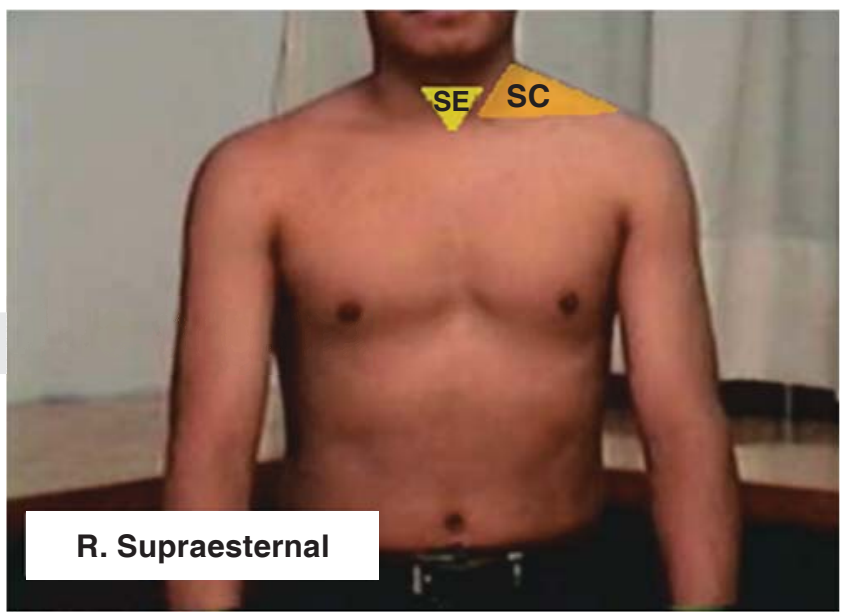

Figura 14. Región supraesternal. 


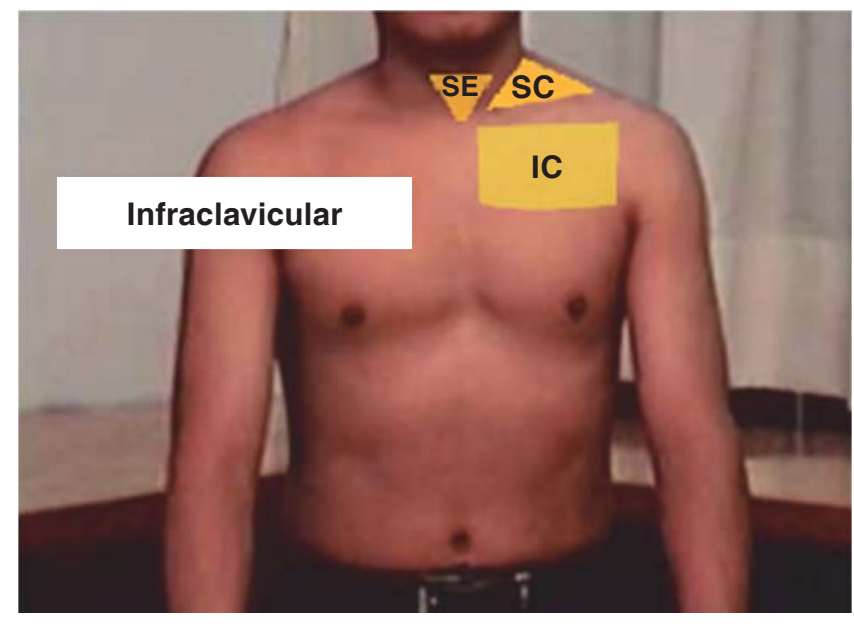

Figura 15. Región infraclavicular.

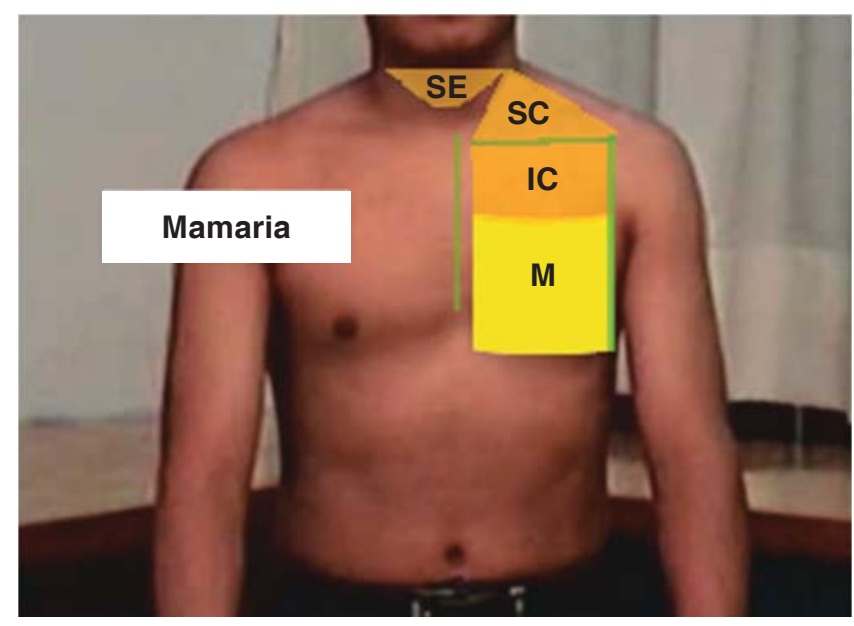

Figura 16. Región mamaria.

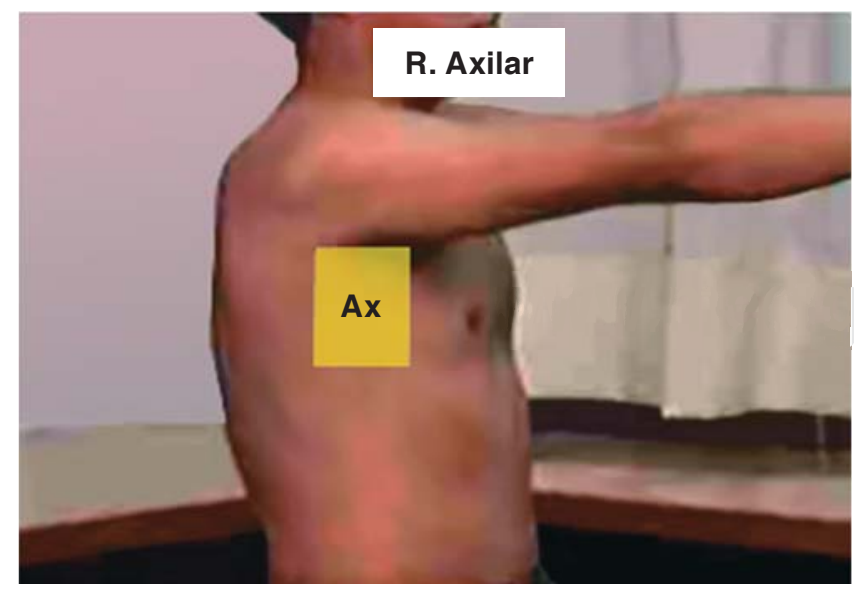

Figura 17. Región axilar. constituyen el hueco axilar y la sexta costilla, respectivamente (figura 17).

- Región infraaxilar. Se extiende desde el límite inferior de la región axilar y el borde que hacen las costillas falsas (figura 18).

\section{Regiones de la cara posterior del tórax}

- Región supraescapular. Está limitada por la columna dorsal, la espina de la escápula y el borde superior del hombro (figura 19).

- Escapular. Se proyecta precisamente sobre la escápula, debido a que es un plano óseo cubierto por grandes masas musculares. Esta región resulta de poca importancia semiológica ya que prácticamente es imposible realizar algún tipo de exploración física (figura 20).

- Región escapulovertebral. Se localiza entre el borde interno de la escápula y de la tercera a la

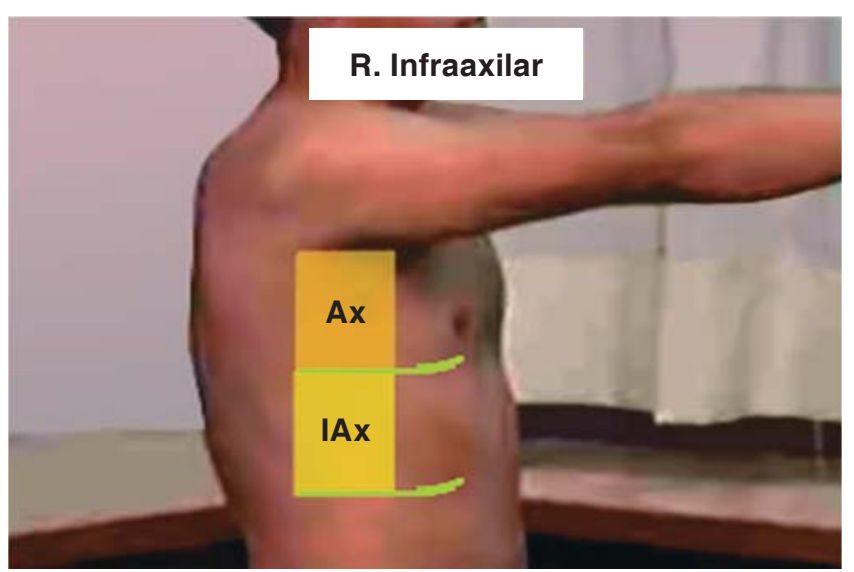

Figura 18. Región infraaxilar.

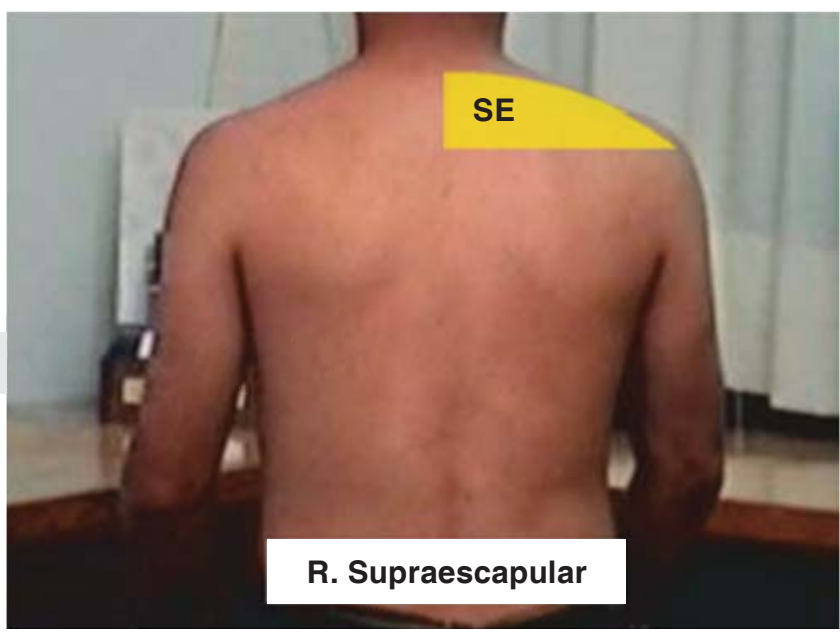

Figura 19. Región supraescapular. 


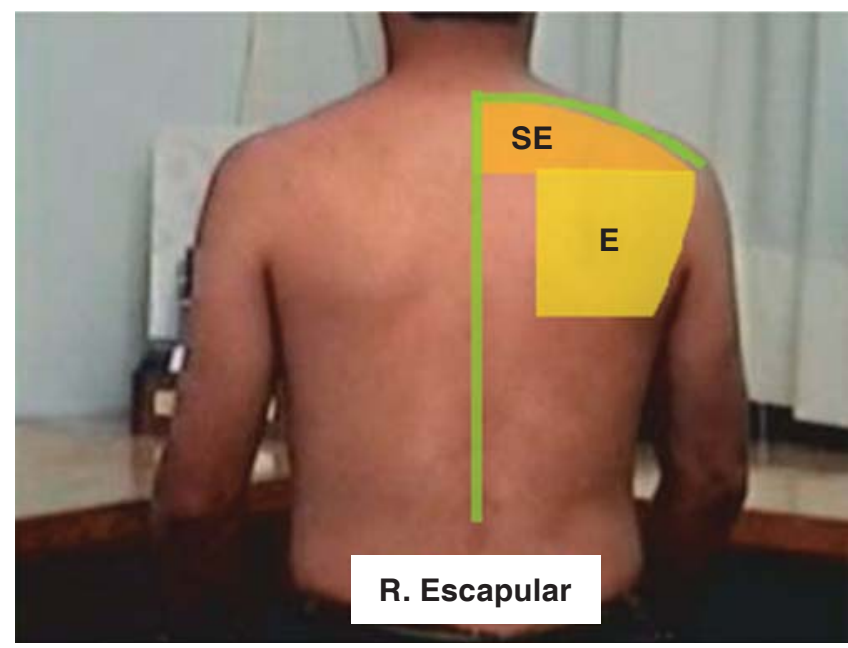

Figura 20. Región escapular.

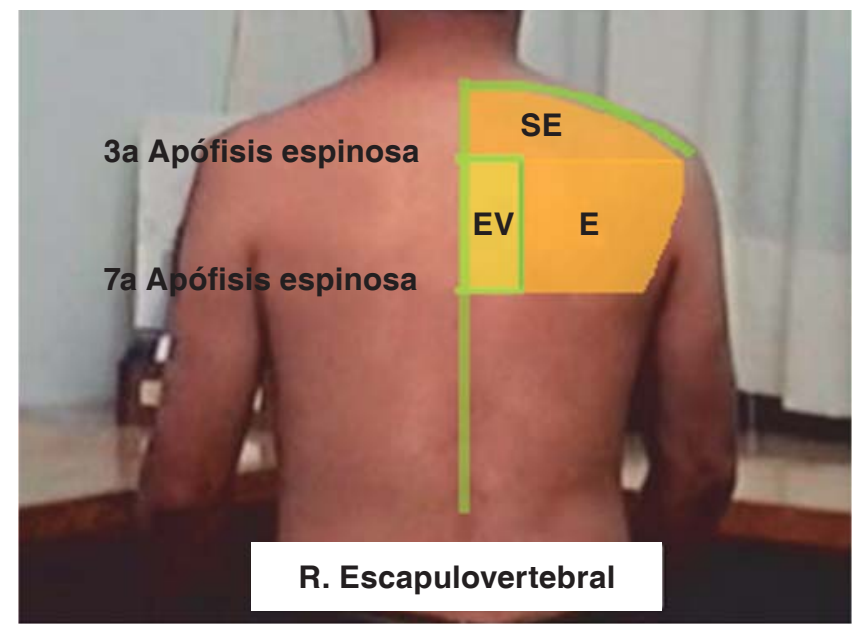

Figura 21. Región escapulovertebral.

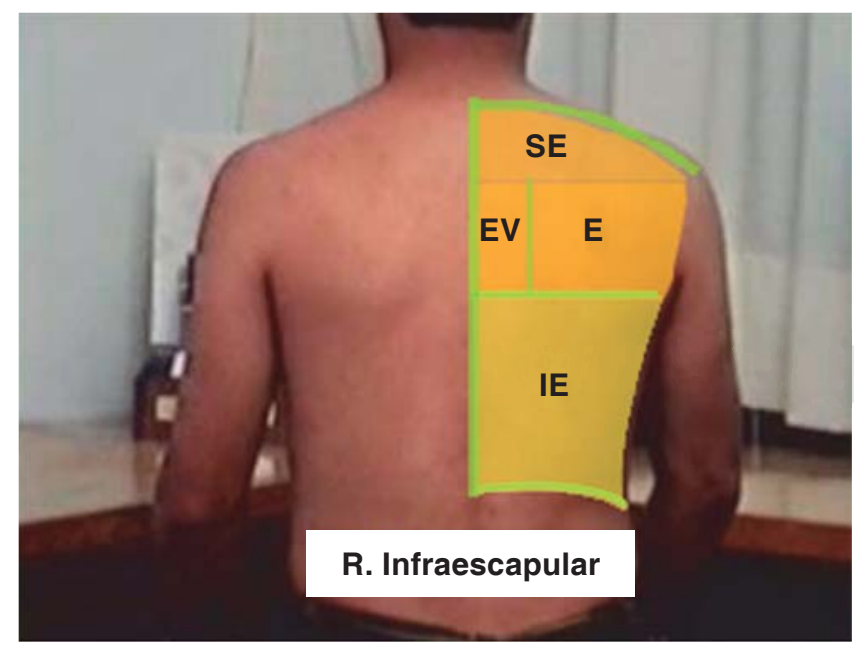

Figura 22. Región infraescapular. séptima apófisis espinosa de la columna dorsal (figura 21).

- Región infraescapular. Se localiza entre la horizontal que pasa por el ángulo de ambas escápulas y la línea duodécima dorsal o basal de Mouriquand (figura 22).

\section{ETAPAS DE LA EXPLORACIÓN FÍSICA DEL TÓRAX}

Después de conocer las líneas y regiones del tórax estamos ya preparados para iniciar el estudio de la exploración física del tórax.

Para realizar la exploración física el paciente puede estar en posición de pie, sentado o acostado en cama, todo depende del estado general de él. Sin embargo, si su estado lo permite, la posición ideal es con el paciente sentado en un banco, con las manos descansando sobre ambas rodillas, el tórax debe estar al descubierto y desde luego siempre cuidando el pudor del paciente (figura 23).

- El lugar donde se lleve a cabo la exploración debe estar bien iluminado, con una temperatura ambiente confortable y con el menor ruido posible.

- La exploración física del tórax comprende cuatro etapas: inspección, palpación, percusión y auscultación.

\section{INSPECCIÓN}

- Consiste en una observación cuidadosa y detallada de la superficie del tórax. Su finalidad es detectar alteraciones de forma, volumen, estado de la superficie y movilidad.

- La inspección es de dos tipos: estática y dinámica.

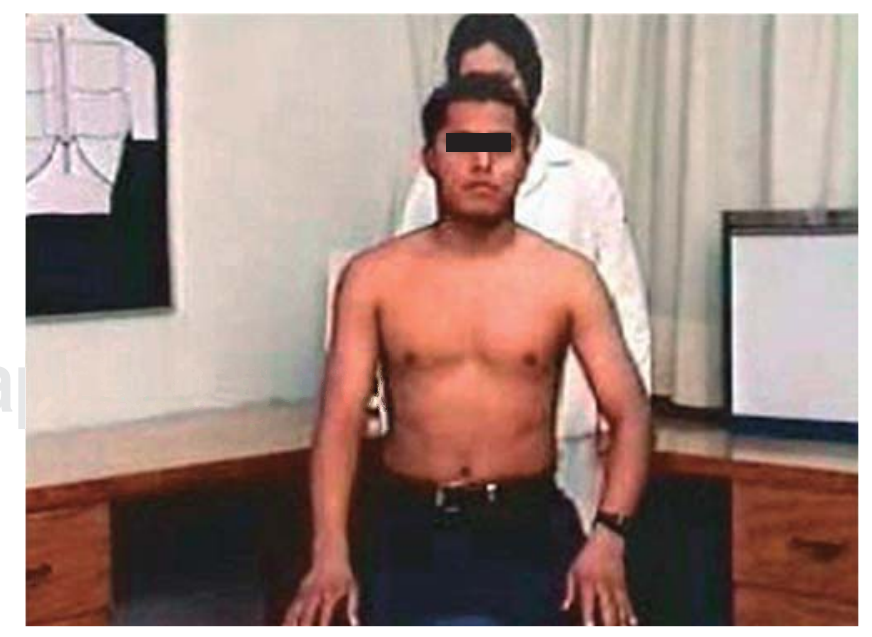

Figura 23. Posición ideal del paciente para la exploración física toracopulmonar. 


\section{Inspección estática}

Durante la inspección estática es posible obtener información del tipo de tórax, deformidades si existen y alteraciones del estado de la superficie. El tórax normal es simétrico en forma y volumen y puede presentar cierta variabilidad que depende de la edad y el sexo del sujeto.

- El tórax en los primeros años de vida es de diámetro vertical pequeño y casi cilíndrico y no presenta diferencias de acuerdo con el sexo.

- En la adolescencia el tórax se alarga y aplana. Ésta es la etapa que marca las diferencias de acuerdo con el sexo y determina finalmente la configuración del tórax del adulto.

- En el anciano el tórax cambia de forma pues ocurre un aumento del diámetro anteroposterior, cambios en la columna vertebral y en las partes blandas.

- En términos generales, la forma del tórax es cónica con el vértice dirigido hacia el abdomen y la base al cuello, sin embargo, en la mujer la morfología tiende a ser más cilíndrica.

- La forma del tórax en sujetos asténicos es alargado y estrecho, en los pícnicos es corto y globoso, y en el caso de los atléticos es un tórax prominente con robustez ósea.

Las deformidades del tórax se dividen en congénitas y adquiridas. A continuación se mencionan algunos ejemplos que caracterizan al primer grupo: tórax acanalado o pectus excavatum, tórax en embudo, tórax piramidal, tórax piriforme.

- Tórax acanalado: presenta un discreto hundimiento longitudinal del esternón.

- Tórax en embudo o pectus excavatum: se caracteriza por una depresión en la región esternal.

- Tórax piramidal: prominencia de la parte anteroinferior de la caja torácica a la altura del apéndice xifoides por excesivo desarrollo costal.

- Tórax piriforme: forma de pera invertida con gran saliente anterosuperior.

En el segundo grupo se incluyen las deformidades adquiridas, así tenemos:

- Tórax raquítico dado por un aumento del diámetro anteroposterior con disminución de los diámetros transversos, aplanamiento desde la línea medioclavicular hasta la línea axilar posterior, por lo común es un tórax propio del raquitismo.
- Tórax enfisematoso: es voluminoso, cilíndrico con aumento del diámetro anteroposterior y del transverso inferior, se observa en casos de enfisema pulmonar.

Las alteraciones de forma pueden ser asimétricas, explicadas por la presencia de abombamiento (como es el caso del derrame pleural o del neumotórax hipertensivo), y por retracción unilateral (como puede ser en la condensación pulmonar o en la atelectasia).

Una vez estudiada la forma y el volumen revisaremos el estado de la superficie, la cual incluye: las características de la piel como su color, la presencia de nevos, acné, cicatrices, estrías, vesículas, manchas, quistes, tumores y la red venosa colateral.

Los músculos no deben parecer atróficos, ni espásticos, la columna no debe presentar desviaciones laterales, posteriores o anteriores.

\section{Inspección dinámica}

- La inspección dinámica permite evaluar las características de los movimientos respiratorios en lo que se refiere a frecuencia, ritmo, amplitud y simetría.

- La respiración normal consiste en movimientos rítmicos sucesivos de expansión del tórax (inspiración) y retracción (espiración).

- El tipo de respiración en los niños es francamente abdominal; en la mujer es costal superior y en el hombre es costal inferior o toracoabdominal.

- Los movimientos respiratorios pueden estar aumentados o disminuidos en número, en intensidad o en ambos aspectos. Pueden ser uni o bilaterales y puede observarse disminución en un hemitórax con aumento en el otro por función vicariante. He aquí la importancia de observar y comparar un hemitórax en relación con el otro.

\section{TIPOS ANORMALES DE RESPIRACIÓN}

La respiración anormal puede ser de dos tipos:

1) Alteraciones en el número y amplitud de las respiraciones por minuto (frecuencia respiratoria) y

2) Trastornos del ritmo respiratorio.

\section{Alteraciones en el número y amplitud de las respiraciones por minuto}

Las alteraciones en el número y amplitud de respiraciones por minuto (frecuencia respiratoria) son: batipnea, taquipnea, polipnea y bradipnea. 
- La batipnea es un tipo de respiración caracterizado por aumento en la amplitud de los movimientos respiratorios sin modificación ostensible de su número.

- La taquipnea se caracteriza por el aumento en la frecuencia respiratoria.

- La polipnea es una respiración superficial.

- La bradipnea se caracteriza por la disminución en el número de respiraciones por minuto o frecuencia respiratoria.

\section{Trastornos del ritmo respiratorio}

Los trastornos del ritmo respiratorio que se pueden observar son los siguientes:

- Respiración de Cheyne-Stokes (ciclopnea), respiración de Kussmaul (respiración grande), respiración de Biot, respiración alternante, respiración suspirosa, etc.

- La respiración de Cheyne-Stokes se caracteriza por períodos prolongados de apneas y períodos de actividad, se inician por pequeños movimientos que van aumentando de forma progresiva para disminuir en la misma forma hasta llegar a la apnea. Este tipo de respiración se presenta en traumatismos craneoencefálicos, hemorragia cerebral, coma urémico, meningitis tuberculosa e intoxicación por opiáceos.

- La respiración de Biot consiste en períodos de apneas con períodos activos de movimientos respiratorios. Las meningitis, los tumores y las hemorragias intracraneanas pueden originarla.

- La respiración de Kussmaul se da por una inspiración profunda y ruidosa seguida por una pausa respiratoria con espiración breve y quejumbrosa seguida de una nueva pausa. Se produce por una estimulación del centro respiratorio por acidosis. Este tipo de respiración se observa en el coma urémico y en el diabético hiperosmolar, no cetoacidótico.

- Respiración paradójica. Ocurre en el caso de fracturas costales múltiples o bilaterales; o bien la costilla se fractura en dos sitios diferentes.

- Otro tipo de alteraciones de la respiración son los tiros intercostales, se caracterizan por la depresión de los espacios intercostales durante la inspiración dada por la presencia de obstrucción intratorácica.

\section{PALPACIÓN}

Después de la inspección continuamos con la palpación. Mediante el tacto superficial se confirman las alteraciones en la superficie del tórax y se intenta explicarlas a través de las bases conceptuales anatómicas existentes, así como también detectar otras anormalidades que escaparon a la inspección. Su finalidad es corroborar la información obtenida en la inspección y agregar más detalles. Brinda información sobre partes blandas y caja torácica, ganglios del cuello y axilas, movimiento respiratorio, frémitos y vibraciones vocales.

\section{Palpación del cuello}

Aunque el cuello es otra región anatómica, su exploración casi siempre forma parte de la exploración del tórax; por lo común, lo que se busca es la presencia de ganglios.

- En el cuello se encuentran alrededor de la mitad de los ganglios del organismo, es un sitio muy accesible a la evaluación clínica del enfermo ya que no sólo los podemos ver y palpar; sino que también se puede realizar una biopsia para estudio histopatológico.

- Los más accesibles para biopsia son los yugulares superiores y preescalénicos.

- Los ganglios pueden crecer como consecuencia de patología de las vías respiratorias altas y bajas, y en otras ocasiones reflejan patología a distancia como neoplasias o infecciones.

- La palpación es bilateral y simultánea para que sea comparativa. Las características de los ganglios en el caso de ser palpables se describirán con base en su número (mono o poliadenitis), tamaño, consistencia, sensibilidad, movilidad y adherencias.

\section{Palpación de la axila}

- Los ganglios de la axila se palparán con el brazo homolateral en tres posiciones para el mejor acceso de los mismos.

\section{Movilidad del tórax}

Para el estudio de la movilidad del tórax se utilizan las maniobras de amplexación superior e inferior y amplexión.

- Para la amplexación superior se colocan las manos sobre ambos huecos supraclaviculares con los pulgares tocando las apófisis espinosas, los dedos medio e índice deberán situarse sobre las clavículas. Las manos del explorador deben de colocarse con suavidad y sin realizar presión para permitir el movimiento libre del tórax (figura 24). 

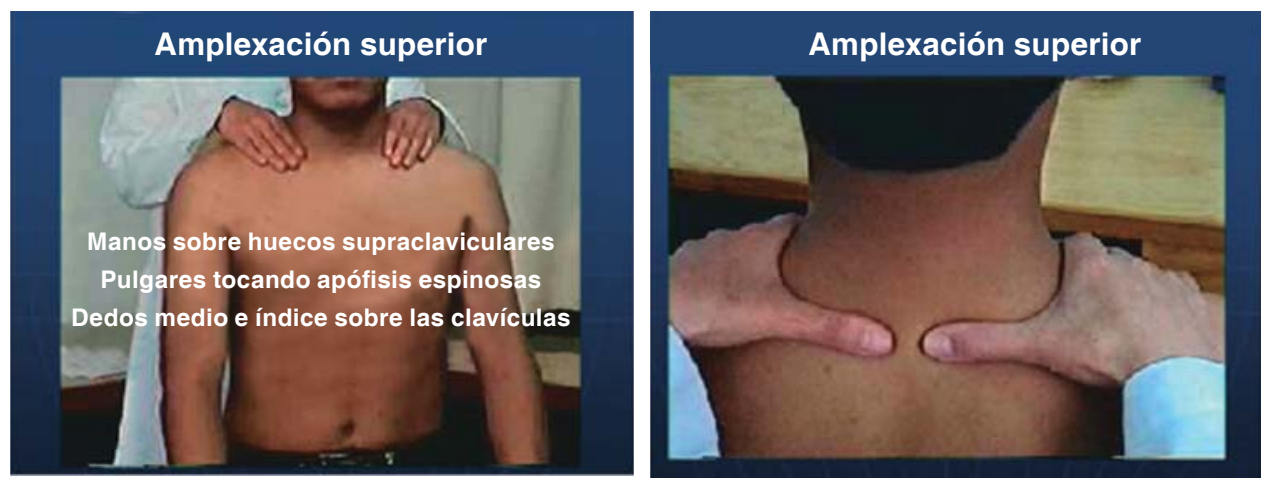

Figura 24. Amplexación superior.

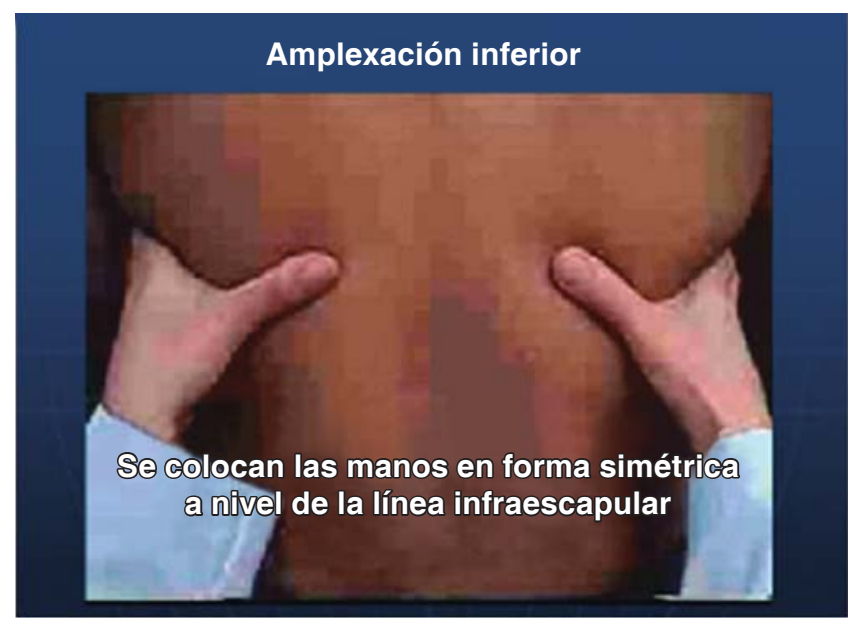

Figura 25. Amplexación inferior.

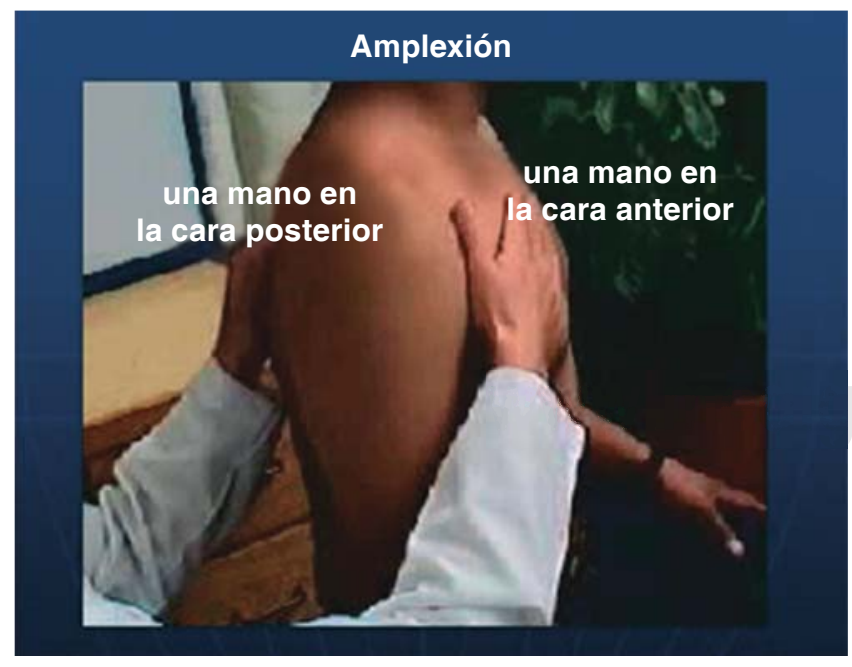

Figura 26. Amplexión.
- En la amplexación inferior se colocan las manos en forma simétrica a nivel de la línea infraescapular con los pulgares lo más separado de la columna vertebral (figura 25).

- La amplexión nos permite precisar la amplitud del movimiento respiratorio en dirección anteroposterior de cada hemitórax; para ello, se coloca una mano en la cara anterior y otra en la cara posterior de cada lado, tanto en la parte superior como inferior del tórax como aquí se muestra.

- Luego se le pide al paciente que inspire y espire profundo, note que el hemitórax debe expanderse de forma simultánea y con la misma amplitud en ambas fases respiratorias (figura 26).

- La transmisión de las vibraciones de las cuerdas vocales durante el habla a través de los bronquios, parénquima pulmonar, pleura y pared torácica produce las vibraciones vocales; éstas se perciben con la sensibilidad táctil de la mano.

- La maniobra consiste en que el sujeto repita con voz bien articulada, con intensidad moderada y lentamente una palabra con «U» y «O como «uno», prolongando el sonido de la «u» y diciendo «UUUUUUNO» (figura 27).

- En la cara anterior se palparán en la región infraclavicular.

Las características de las vibraciones vocales se explorarán de forma sistemática y siempre comparativa con el lado contralateral y se realizarán en todas las caras del tórax.

En la cara anterior se palparán en la región infraclavicular; en la cara lateral en las regiones axilar e infraaxilar; y en la cara posterior, en las regiones supraescapular, escapulovertebral y subescapular.

Situaciones clínicas en donde las vibraciones vocales están alteradas: 

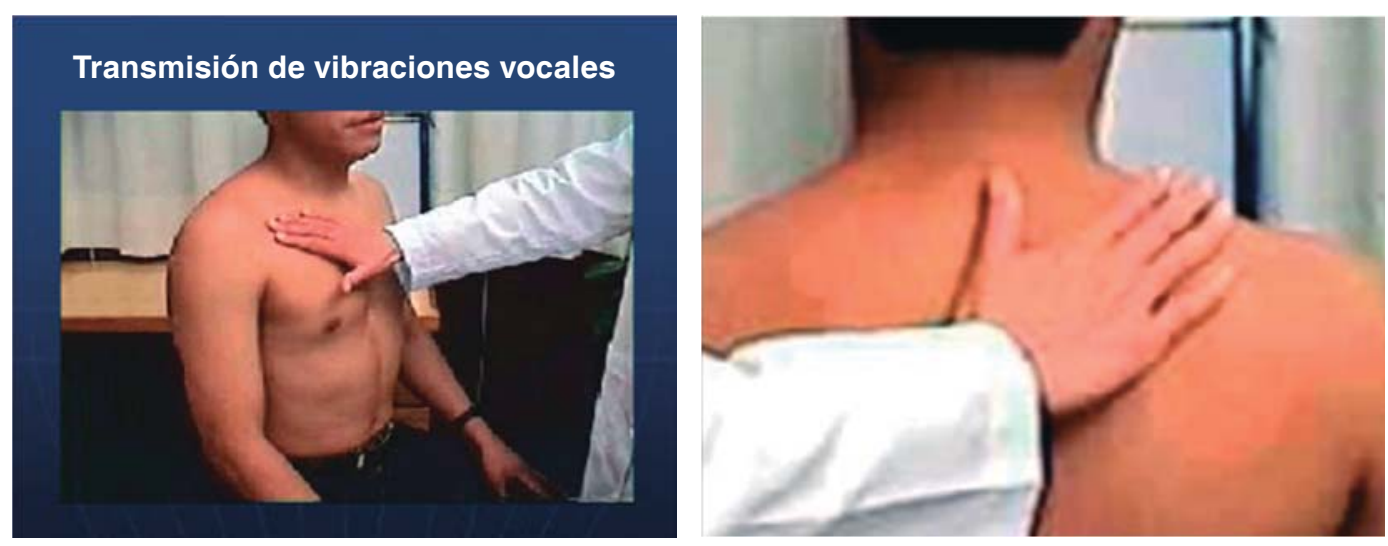

Figura 27. Transmisión de vibraciones vocales.

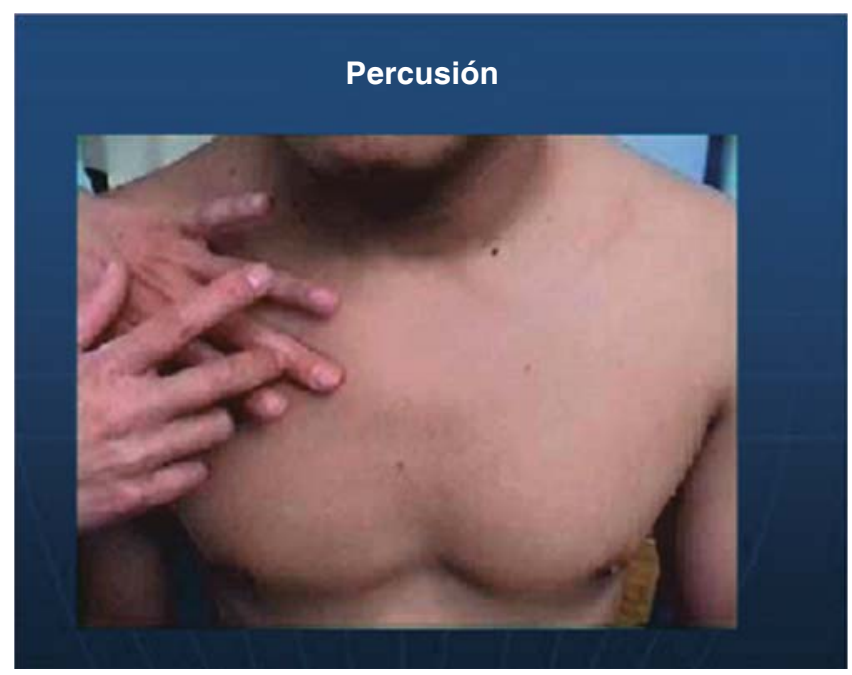

Figura 28. Percusión del tórax.

- En la condensación pulmonar aumentan las vibraciones vocales, mientras que en las lesiones de faringe la presencia de un cuerpo extraño, una masa tumoral, el tórax senil, el derrame pleural y el neumotórax se palparán disminuidas.

\section{PERCUSIÓN}

Se utiliza la transmisión de una onda sonora y la reflexión de la misma para obtener información no superficial del tórax. Su finalidad es determinar la naturaleza de la alteración y ubicar la profundidad de la lesión.

La maniobra consiste en golpear suave la superficie del tórax, con el fin de obtener sonidos cuyas características nos permiten reconocer la naturaleza física de la alteración y los límites del pulmón subyacente (figura 28).
- La percusión es de dos tipos: comparativa, con ella es posible reconocer el sonido normal en una misma región; y la percusión topográfica se utiliza para limitar los contornos de los órganos.

- Existen diferentes métodos para realizar la percusión; sin embargo, la que se utiliza para la exploración del tórax es la llamada mediata o dígito-digital. Consiste en colocar sobre la superficie del cuerpo a explorar un dedo, ya sea el medio o el índice (dedo plesímetro) y con otro dedo (el percutor) se realizarán los golpes para obtener el sonido. El dedo plesímetro se coloca sobre la superficie y los dedos restantes deben estar levantados y separados de la piel.

- Durante la percusión, los movimientos de la mano que percute deben realizarse a nivel de la articulación metacarpofalángica, permaneciendo inmóvil el antebrazo. El golpe debe ser rápido, suave, superficial y de la misma intensidad, el dedo percutor se retira lo más pronto posible una vez obtenido el sonido.

- La percusión, igual que la palpación debe ser comparativa y metódica. Se deberá realizar en las caras posterior, anterior y lateral del tórax siguiendo las regiones ya descritas para la palpación y empleando la misma fase respiratoria.

- Los sonidos obtenidos a la percusión son de tres tipos: el primero, corresponde al claro pulmonar, el cual se obtiene al percutir el tejido pulmonar normal. El segundo, corresponde a la matidez, el cual es resultado de percutir sobre el hígado y el corazón. Por último, el sonido timpánico el cual se genera al percutir el estómago.

- La sonoridad a la percusión puede estar disminuida y como ejemplos de enfermedad tenemos la condensación pulmonar y el derrame pleural; cuando la sonoridad está incrementada debemos descartar la presencia de enfisema y neumotórax. 


\section{AUSCULTACIÓN}

La auscultación es la última fase de la exploración física del tórax. Se realiza con el estetoscopio, el cual es una herramienta muy útil para estudiar las características del sonido respiratorio y poder clasificarlo en normal y anormal.

- Se requiere de una habitación con temperatura confortable y aislada del ruido. Al igual que para las otras técnicas de exploración, la auscultación se debe realizar en forma sistemática y comparativa, para ello es necesario recordar las líneas y regiones del tórax.

- Los ruidos se auscultan en las superficies anterior, lateral y posterior del tórax.

- La secuencia que se debe seguir es la que se indica a continuación: en la cara posterior del tórax comprende diez sitios en los que se incluye a la cara lateral del tórax.

- La auscultación se inicia en la región supraescapular izquierda y a partir de este punto se sigue una secuencia descendente por las regiones interescapulares, infraescapulares y axilares, siempre deberá ser comparativa en el mismo nivel de localización, entre el lado derecho e izquierdo. Cuando el ruido es anormal, éste puede estar aumentado, disminuido o ausente en comparación con el lado contralateral al mismo nivel.

- La cara anterior del tórax comprende nueve sitios, cuya secuencia es similar a lo descrito anteriormente para la cara posterior. Se inicia en la región supraclavicular derecha, siguiendo las líneas paraesternales, pasando por la línea axilar anterior hasta el sexto-séptimo espacio intercostal (figura 29).

\section{Ruido respiratorio}

El ruido respiratorio normal que se ausculta está compuesto por dos ruidos: el laringotraqueal (también denominado soplo glótico) y el murmullo vesicular. A continuación se describen.

- Ruido laringotraqueal. Se le conoce también como respiración bronquial de Laennec, es un ruido soplante de tonalidad elevada que se escucha tanto durante la inspiración como durante la espiración. Se escucha a nivel de la laringe, la tráquea y el esternón; en la parte posterior se ausculta a lo largo de la columna vertebral y en la parte interna de los espacios escapulovertebrales. Este ruido se debe al paso del aire por la hendidura de la glotis. Como las cuerdas vocales están más cerradas durante la espiración, el ruido se escucha con mayor intensidad durante esta etapa del ciclo respiratorio.

- Murmullo vesicular. Se escucha en todos los sitios en los que el tejido pulmonar está en contacto con la pared torácica. Los sitios en los que se escucha con mayor claridad son: las axilas, debajo de las clavículas y en las regiones infraescapulares. Se escucha como un soplo muy suave y es un ruido inspiratorio continuo. Es el resultado de la suma de los ruidos que se producen por la aspiración del aire que distiende millones de alvéolos bruscamente. Durante la espiración este ruido es más suave, menos intenso y también continuo y sólo se escucha al principio de la espiración.

Además de clasificar al ruido respiratorio como normal, aumentado, disminuido o ausente, también es

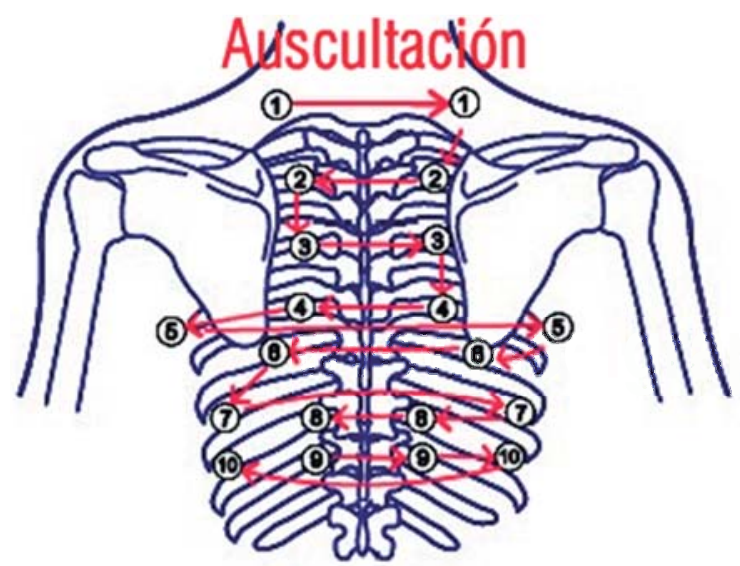

Pared posterior del tórax

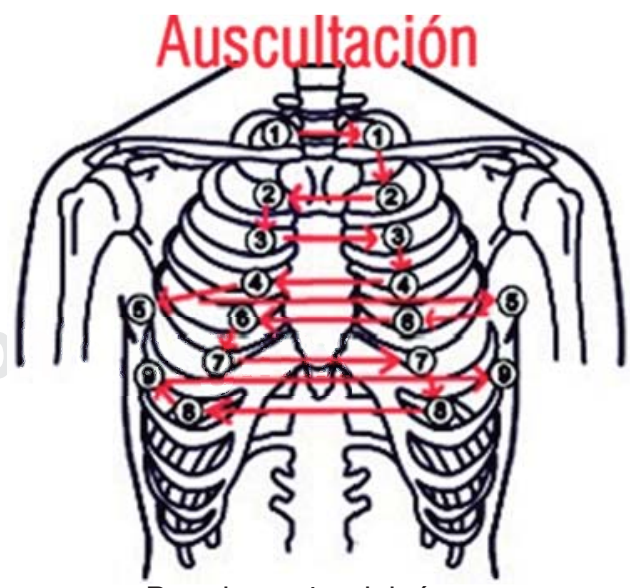

Pared anterior del tórax

Figura 29. Sitios para realizar la auscultación del tórax en sus caras posterior y anterior. 
posible auscultar otro tipo de ruidos agregados anormales, los cuales se producen por la distorsión de la arquitectura broncopulmonar durante el paso del aire a través de la vías respiratorias, nos referimos a los soplos, estertores o resonancia vocal, los cuales se describen y definen a continuación.

\section{Soplos}

- Tubario. Percepción del ruido laringotraqueal en las paredes del tórax. Se escucha en los casos en el que el tejido pulmonar es homogéneo, como cuando hay una neumonía y los bronquios estén permeables.

- Cavitario. Es una modificación del tubario porque hay una cavidad rodeada de tejido pulmonar condensado. Ocurre porque la cavidad sirve como una cámara de resonancia.

- Anfórico. Poco intenso con resonancia metálica. En ocasiones sólo se escucha haciendo al paciente toser o con respiraciones profundas. Puede auscultarse en casos de neumotórax espontáneo a tensión.

- Pleurítico. Es un soplo tubárico modificado, de preferencia espiratorio. Se escucha más claro en la zona en la que el pulmón está rechazado, entre la columna vertebral y la escápula.

\section{Estertores}

Son ruidos anormales que acompañan a los respiratorios normales a los que pueden modificar. Unos tienen su origen en los bronquios o en el pulmón y otros en la cavidad pleural. Cada uno tiene un significado semiológico diferente.

- Traqueal. Ocurre por la presencia de secreciones en la laringe, tráquea o bronquios gruesos y que el paciente no puede expulsar.

- Roncantes. Se pueden producir por la presencia de moco espeso o por la disminución de la luz por la contracción del músculo bronquial y edema de la mucosa. A la palpación pueden acompañarse de la sensación táctil de frémito.

- Silbantes y piantes. Se presentan por la obstrucción de bronquios de pequeño calibre y se distinguen por su tonalidad aguda.

- Crepitantes. Se auscultan al final de la inspiración y son la consecuencia de la distensión de los alvéolos que están llenos de material fibrinoleucocitario y el material se despega de sus paredes. Su sonido es semejante al que se escucha cuando se frota un mechón de cabello cerca del oído.
- Subcrepitantes. Se auscultan a lo largo de todo el ciclo respiratorio, se modifican con la tos.

- Frote pleural. Se ocasiona por el roce de las hojas pleurales por la presencia de un proceso inflamatorio, por lo regular, al final de la inspiración. No se propagan y en donde se escucha mejor es en las regiones subescapulares.

\section{Resonancia vocal}

Se explora cuando el sujeto habla y repite palabras con muchas consonantes. En el sujeto normal la sensación sonora es poco intensa, confusa, que no permite identificar las sílabas. Ésta se conoce como broncofonía fisiológica.

- Broncofonía. La voz llega al oído con mayor intensidad y resonancia que en condiciones normales. Se encuentra en zonas de condensación pulmonar.

- Pectoriloquia. Se encuentra en las zonas de condensación, pero a diferencia de la broncofonía, aquí las palabras se reconocen con claridad. Se le llama áfona, cuando la voz del paciente que cuchichea se oye con claridad. Esto ocurre en la condensación y en la pleuritis seca.

- Egofonía. Modificación de la voz transmitida que se escucha estridente, aguda y con un carácter tembloroso. Es característica de las pleuritis, se escucha en el borde de los derrames.

\section{Síndromes pleuropulmonares}

En la cínica se entiende como síndrome al conjunto sistematizado de signos recogidos de la exploración física y síntomas de una enfermedad, es así que los procesos patológicos del pulmón y de la pleura modifican la fisiología normal de las diferentes estructuras contenidas en la caja torácica.

Los hallazgos identificados durante la inspección, palpación, percusión y auscultación del tórax permiten obtener signos que al agruparlos se integran en los llamados síndromes pleuropulmonares.

Los síndromes pulmonares son: condensación, atelectasia, rarefacción y cavitario; y los pleurales son el derrame pleural, neumotórax y la combinación de ambos o hidroneumotórax. A continuación se describe cada uno de ellos (tabla 1).

\section{Síndrome de condensación}

Es el resultado de cambios físicos que producen llenado del alvéolo de algún material distinto al aire, como en el 
Tabla 1. Síndromes pulmonares y pleurales. ${ }^{1}$

\begin{tabular}{|c|c|c|c|c|c|c|}
\hline & Condensación & Atelectasia & Cavitario & Rarefacción & Derrame & Neumotórax \\
\hline $\begin{array}{l}\text { Inspección } \\
\text { estática }\end{array}$ & $M R \Downarrow$ & $\mathrm{MR} \Downarrow$ & MR $\Downarrow$ & $\begin{array}{c}\text { MR } \Downarrow \\
\text { Tórax en tonel }\end{array}$ & MR $\Downarrow$ & $M R \Downarrow$ \\
\hline $\begin{array}{l}\text { Inspección } \\
\text { dinámica }\end{array}$ & $\begin{array}{c}\text { AMP } \Downarrow \\
\text { AMPX } \Downarrow\end{array}$ & $\begin{array}{c}\text { AMP } \Downarrow \\
\text { AMPX } \Downarrow \\
\text { en hemitórax } \\
\text { afectado }\end{array}$ & $\begin{array}{l}\text { AMP } \Downarrow \\
\text { AMPX } \Downarrow\end{array}$ & $\begin{array}{c}\text { AMP } \Downarrow \\
\text { AMPX } \Downarrow\end{array}$ & $\begin{array}{c}\text { AMP } \Downarrow \\
\text { AMPX } \Downarrow \\
\text { en hemitórax } \\
\text { afectado }\end{array}$ & $\begin{array}{c}\text { AMP } \Downarrow \\
\text { AMPX } \Downarrow \\
\text { en hemitórax } \\
\text { afectado }\end{array}$ \\
\hline Palpación & $\begin{array}{l}\mathrm{MR} \Downarrow \\
\mathrm{TVV} \Uparrow\end{array}$ & $\begin{array}{l}\mathrm{MR} \Downarrow \\
\mathrm{TVV} \Downarrow\end{array}$ & 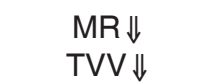 & $\begin{array}{l}\mathrm{MR} \Downarrow \\
\mathrm{TVV} \Downarrow\end{array}$ & $\begin{array}{l}\mathrm{MR} \Downarrow \\
\mathrm{TVV} \Downarrow\end{array}$ & $\begin{array}{l}\mathrm{MR} \Downarrow \\
\mathrm{TVV} \Uparrow\end{array}$ \\
\hline Percusión & Mate & Mate o submate & $\begin{array}{l}\text { Hiperclaridad } \\
\text { localizada }\end{array}$ & Hipersonoridad & $\begin{array}{l}\text { Mate } \\
\text { en hemitórax } \\
\text { afectado }\end{array}$ & $\begin{array}{l}\text { Hipersonoridad } \\
\text { en hemitórax } \\
\text { afectado }\end{array}$ \\
\hline Auscultación & $\begin{array}{l}\mathrm{TVV} \Uparrow \\
\mathrm{RR} \Uparrow\end{array}$ & $\begin{array}{l}\mathrm{TVV} \Downarrow \\
\mathrm{RR} \Downarrow\end{array}$ & $\begin{array}{l}\mathrm{TVV} \Downarrow \\
\mathrm{RR} \Downarrow\end{array}$ & $\begin{array}{l}\mathrm{TVV} \Downarrow \\
\mathrm{RR} \Downarrow\end{array}$ & $\begin{array}{c}\text { TVV } \Downarrow \\
\text { RR } \Downarrow \\
\text { en hemitórax } \\
\text { afectado }\end{array}$ & $\begin{array}{c}\text { TVV } \Downarrow \\
\text { RR } \Downarrow \\
\text { en hemitórax } \\
\text { afectado }\end{array}$ \\
\hline Soplos & $\begin{array}{l}\text { Tubario o } \\
\text { cavitario }\end{array}$ & & & & Frote & Anfórico \\
\hline Estertores & Roncantes & & & $\begin{array}{c}\text { Crepitantes o } \\
\text { roncantes }\end{array}$ & & \\
\hline Pectoriloquia & Áfona & & & & $\begin{array}{c}\text { Áfona en el borde } \\
\text { del derrame }\end{array}$ & \\
\hline
\end{tabular}

MR: Movimientos respiratorios AMP: Amplexación AMPX: Amplexión RR: Ruidos respiratorios
$\Uparrow$ Aumento

$\Downarrow$ Disminución TVV: Transmisión de las vibraciones vocales

${ }^{1}$ Modificado de Rivero-Serrano O, Navarro-Reynoso F. Neumología. 6ta. Ed. México: Trilla; 2009.

caso de infecciones tales como neumonía bacteriana, tuberculosis, o bien tumores.

A la inspección la movilidad del hemitórax afectado se encuentra disminuida por disminución de la elasticidad del pulmón. A la palpación, las maniobras de amplexión y amplexación corroboran dicha disminución de la movilidad y las vibraciones vocales están aumentadas debido a que esa parte del pulmón transmite más vívidamente los sonidos, tal como lo haría un medio sólido. A la percusión, la sonoridad está disminuida o abolida y se percute más bien un sonido mate o submate. A la auscultación, el ruido respiratorio se encuentra aumentado de intensidad, además de que puede escucharse un soplo «tubario» parecido al sonido producido por el paso del aire al soplar a través de un tubo. Puede haber también fenómenos agregados como estertores.

\section{Síndrome de atelectasia}

Se produce cuando se obstruye un bronquio ya sea por vía intrínseca como un tumor o cuerpo extraño dentro del mismo, o bien por vía extrínseca como una compresión ocasionada por una tumoración que se encuentre fuera de la luz del bronquio. En cualquiera de estas situaciones, la consecuencia producida es que el aire que se encuentra dentro de los alvéolos es absorbido por la sangre circulante y se produce la atelectasia, lo que conlleva a una disminución del volumen del pulmón afectado, reduciendo así su tamaño y causando retracción de las estructuras que están adyacentes al mismo.

A la inspección los hallazgos deben buscarse desde la exploración del cuello, en el cual la palpación de la tráquea denotará una retracción de la misma hacia el hemitórax afectado, existe disminución del tamaño de los espacios intercostales del tórax óseo, con disminución del tamaño del hemitórax afectado y de los movimientos del mismo. A la palpación, las maniobras de amplexión y amplexación se encuentran disminuidas y las vibraciones vocales están disminuidas o ausentes; la percusión será mate o submate y no se auscultan ruidos respiratorios ni la transmisión de la voz pues el parénquima pulmonar se encuentra colapsado al igual que los bronquios dentro del mismo. 


\section{Síndrome cavitario}

Es el resultado de la destrucción del parénquima pulmonar con formación de una caverna de paredes gruesas que circunda una zona con ausencia de tejido, misma que se encuentra llena de aire, siempre y cuando no tenga un proceso infeccioso sobreagregado ya sea por hongos o bacterias. Los ejemplos clásicos son las cavernas por tuberculosis, quistes, bulas, neumatoceles o hasta abscesos pulmonares.

A la inspección observamos un descenso de los movimientos respiratorios del lado afectado, la palpación muestra las maniobras de amplexión y amplexación disminuidas y las vibraciones vocales también. A la percusión encontramos una zona limitada de hiperclaridad. En la auscultación se puede percibir un «soplo anfórico o soplo cavitario» que es semejante al producido al soplar aire a través de una botella de forma horizontal, el ruido respiratorio va a estar ausente debido a la ausencia de parénquima pulmonar que lo transmita. Sin embargo, en la periferia de la cavitación se pueden encontrar los mismos datos que en una condensación pulmonar como resultado de la neumonitis que circunda a la cavidad.

\section{Síndrome de rarefacción}

Es característico de los pacientes que tienen enfisema pulmonar. La forma del tórax es el llamado «tórax en tonel». El movimiento respiratorio, las maniobras de amplexión y amplexación, las vibraciones vocales, el ruido respiratorio y la transmisión de la voz se encuentran disminuidos, a la percusión en vez de encontrar claro pulmonar se percute hiperclaridad generalizada.

\section{Síndrome de derrame pleural}

Se presenta cuando el líquido contenido en el espacio entre ambas pleuras incrementa tanto que supera la reabsorción del mismo. Existen seis mecanismos para que ello suceda y da como resultado que a la inspección, el movimiento respiratorio del hemitórax afectado se encuentra bajo, las maniobras de amplexión y amplexación van a estar disminuidas lo mismo que las vibraciones vocales por debajo del nivel del derrame, se percute mate y a la auscultación el ruido respiratorio se encuentra disminuido o ausente al igual que la transmisión de la voz.

Es importante recordar que en ocasiones la única manera para diferenciar un derrame pleural de una atelectasia es encontrar desplazamiento o retracción de la tráquea hacia el lado afectado ya que ambos síndromes son muy similares.

\section{Síndrome de neumotórax}

Presente cuando hay aire en el espacio entre ambas pleuras como resultado de la ruptura de la pleura visceral permitiendo dicha fuga, hecho favorecido por la presión negativa de la cavidad, igualándola con la presión atmosférica, lo que produce colapso pulmonar.

A la exploración física se encuentra descenso del movimiento respiratorio, al igual que las maniobras de amplexión y amplexación. Las vibraciones vocales, la transmisión de la voz y el ruido respiratorio se encontrarán ausentes, a la percusión encontramos timpanismo en el hemitórax afectado.

\section{Síndrome de hidroneumotórax}

Se presenta cuando además de líquido existe aire en la cavidad pleural como resultados de una fístula broncopleural, o de forma iatrógena al introducir aire durante la toracocentesis de un derrame pleural.

Se caracteriza por la combinación de ambos síndromes, tanto de neumotórax que se encuentra en la parte superior del hemitórax afectado, como de derrame pleural que se encuentra en la parte inferior del mismo, esto secundario al efecto que produce la gravedad.

\section{Agradecimientos}

Al Dr. Enrique Olvera Masetto y al equipo de la Oficina Audiovisual del INER: DI. Daniel Ávila García, DG. Hilding Barbosa Hermosillo, DG. Evangelina Torres Olguín. Colaboradores en Servicio Social en la Oficina de Audiovisual: C. Lorenzo Antonio García Hernández y Oscar Pérez López de la Escuela Nacional de Artes Plásticas.

\section{REFERENCIAS}

1. García-Aretio L. La educación a distancia. De la teoría a la práctica. España: Ariel; 2001.

2. Fainholc B. La interactividad en la educación a distancia. Buenos Aires: Paidós; 2006.

\section{BIBLIOGRAFÍA}

- Surós BA, Surós BJ. Semiología médica y técnica exploratoria. 8 ${ }^{\text {a }}$. ed. Madrid: Elsevier Masson; 2001. 
- Argente HA, Álvarez ME. Aparato respiratorio. Parte VIII. Semiología médica. Fisiopatología, semiotécnica y propedéutica. Enseñanza basada en el paciente. Buenos Aires: Médica Panamericana; 2008.

- Bernard M. Tecnología y formación. En: Bernard M, editor. Formación, distancias y tecnología. Barcelona: Pomares; 2006: 54-74.

- García-Aretio L. La educación a distancia. De la teoría a la práctica. España: Ariel; 2001. p. 151-161.

- González-Catelan Y. El video tutorial como herramienta de apoyo pedagógico. 2013. Fecha de consulta: 23-112015. Accesible en: http://www.uaeh.edu.mx/scige/ boletin/prepa4/n1/e8.html

- Rivero-Serrano O, Navarro-Reynoso F. Neumología. 6ta. ed. México: Trillas; 2009.
- Surós BA, Surós BJ. Neumología. En: Surós BA, Surós BJ, editores. Semiología médica y técnica exploratoria. 8va. Ed. Barcelona: Elsevier Masson; 2001. p. 63-186.

\section{$\triangle$ Correspondencia:}

Lic. Rebeca Ortiz-Siordia

Jefa del Departamento de Educación Continua, Instituto Nacional de Enfermedades Respiratorias Ismael Cosío Villegas.

Calzada de Tlalpan Núm. 4502,

Colonia Sección XVI, 14080,

Ciudad de México.

Teléfono: (52) 5554871700, ext. 5207

Correo electrónico: ros@iner.gob.mx

Los autores declaran no tener conflicto de intereses. 